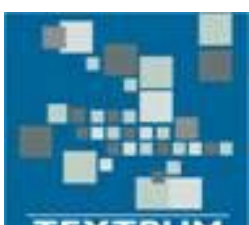

TEXTRUM

\title{
The Attraction of Sugar: An Association between Body Mass Index and Impaired Avoidance of Sweet Snacks
}

\author{
Joyce Maas ${ }^{a}$, Marcella L. Woud ${ }^{b}$, Ger P.J. Keijsers ${ }^{a, c}$, Mike Rinck ${ }^{a}$, Eni S. Becker ${ }^{a}$, and \\ Reinout W. Wiers ${ }^{d}$ \\ a Behavioural Science Institute, Radboud University Nijmegen, The Netherlands. \\ ${ }^{b}$ Mental Health Research and Treatment Center, Department of Psychology, University of Bochum, Germany \\ ${ }^{c}$ Clinical Psychological Sciences, Maastricht University, The Netherlands \\ d Addiction, Development and Psychopathology (ADAPT) lab, University of Amsterdam, The Netherlands
}

\begin{abstract}
The present study investigated implicit approach-avoidance action tendencies towards snack foods (pictorial Approach-Avoidance Task), implicit approach-avoidance associations (verbal approach-avoidance Single-Target IAT) and affective associations (verbal positive-negative Single-Target IAT) with snack foods in a group of unselected student participants $(N=83)$. Participants with higher BMI scores had more difficulty to avoid sweet, but not salty snack foods on the Approach-Avoidance Task. Furthermore, as shown by both Single-Target IATs, there were no significant associations between BMI on the one hand and approach-avoidance associations and positive-negative affective associations on the other hand. BMI did show a positive correlation with errors made on all tasks. The results found on the Approach-Avoidance Task suggest that not increased approach, but impaired avoidance of sweet snacks, might be related to increased BMI. However, more research is needed to further disentangle these findings.
\end{abstract}

(c) Copyright 2016 Textrum Ltd. All rights reserved.

Keywords: Body Mass Index, implicit processes, action tendencies, approach/avoidance, affective associations Correspondence to: Joyce Maas, Department of Medical and Clinical Psychology, Tilburg University, P.O. Box 90153, 5000 LE, Tilburg, the Netherlands. E-mail: j.maas@uvt.nl

Received 12-Nov-2015; received in revised form 14-Mar-2016; accepted 05-Apr-2016 


\title{
Table of Contents
}

\author{
Introduction \\ Methods \\ Participants \\ Materials and procedure \\ Approach-Avoidance Task \\ Single-Target IAT \\ Rating task \\ Statistical analyses \\ Results \\ Approach-Avoidance Task \\ Single-Target IAT Approach-avoidance \\ Single-Target IAT Positive-negative \\ Rating Task \\ Exploratory analyses: food preference \\ Correlations \\ Discussion \\ References \\ Appendix
}

\section{Introduction}

Food is abundantly available in our everyday environment. The facts that we have evolved to defend against body weight loss and live in an 'obesogenic' environment contribute to the current 'obesity epidemic' (Hill \& Peters, 1998). In 2009 and 2010, approximately 35\% of the American adult population was obese (Ogden, Carroll, Kit, \& Flegal, 2012). Additionally, the fact that much of our behaviour is guided by automatic processes (e.g., Strack \& Deutsch, 2004), such as the automatic tendency to attend to or approach tempting food cues, helps to understand why many people are overweight. Indeed, a vast amount of research shows that attractive food cues activate automatic approach tendencies (e.g., Brignell, Griffiths, Bradley, \& Mogg, 2009; Veenstra \& De Jong, 2010) and draw people's attention (Mogg, Bradley, Field, \& De Houwer, 2003).

Using a manikin task (De Houwer, Crombez, Baeyens, \& Hermans, 2001), Veenstra and de Jong (2010), for example, found a relatively strong approach tendency in restrained eaters, i.e., people who intentionally aim to achieve or maintain a desired weight by reducing their caloric intake (Van Strien, Frijters, Bergers, \& Defares, 1986). During this task, participants moved a manikin figure towards (representing a symbolic approach movement) or away (representing a symbolic avoidance movement) from high-fat food, low-fat food, and neutral pictures. Restrained eaters were faster to move the manikin towards food: They exhibited an approach bias for high-fat and low-fat food pictures compared to neutral pictures. Brignell et al. (2009) obtained similar results in a sample of external eaters, i.e., people who eat in response to external food cues, such as sight and smell (Van Strien et al., 1986), who exhibited an implicit approach tendency towards high-fat and low-fat food on the manikin task. Havermans, Giesen, Houben, and Jansen (2011), employed a manikin task in a sample of overweight individuals. Stimuli consisted of high-fat and low-fat foods as well as neutral pictures. In contrast to the studies by Veenstra and de Jong, and Brignell and colleagues, who both looked at approach and avoidance as the opposite sides of the same dimension by using difference scores, Havermans et al. looked at approach and avoidance separately. Results showed that overweight men (but not women) were slower to avoid food-related stimuli than neutral stimuli, i.e., they showed impaired avoidance of food stimuli. The women in this study were more ambivalent, reflected by a nearly as fast approach towards and avoidance of high-caloric food. Given these findings, it thus seems that food-related action tendencies can manifest themselves as either faster food approach or as slower food avoidance.

Kemps, Tiggeman, Martin, and Elliott (2013) took a slightly different approach to assess approach-avoidance biases. Using an Implicit Association Test (IAT; Greenwald, McGhee, \& Schwartz, 1998), they compared approach- and avoidance related associations (instead of approach- and avoidance tendencies) with chocolate to associations with 
other highly desired food. Although participants were not specifically selected for a strong liking for chocolate, only females were included, because, as Kemps et al. argued, food cravings are more prevalent in women than in men. All participants indicated that they liked chocolate on a yes/no question preceding the experiment. Results showed that participants were fastest on trials pairing chocolate with approach words, indicating stronger approach-related associations towards chocolate than towards other highly desired foods. This approach-avoidance IAT has also been used in smoking (e.g., De Houwer, Custers, \& De Clerq, 2006) and alcohol (e.g., Palfai \& Ostafin, 2003) research.

In addition to automatic approach and avoidance tendencies, several other automatic processes have been studied in relation to eating in various samples (overweight youngsters, obese adults, or restrained eaters). Studies that focused on positive-negative associations with food stimuli have produced inconsistent results. Using the Extrinsic Affective Simon Task (EAST; De Houwer, 2003), the IAT (Greenwald et al., 1998), or the Affective Priming Task (APT; Fazio, Sanbonmatsu, Powell, \& Kardes, 1986), several studies showed relatively stronger positive implicit associations with high-fat food than controls (e.g., Craeynest et al., 2005 [obese children]; Hoefling \& Strack, 2008 [restrained eaters]). Other studies, however, failed to find such positive associations (e.g., Craeynest, Crombez, Haerens, \& De Bourdeaudhuij, 2007 [overweight youngsters]), or reported even a negative association with high-fat food (e.g., Papies, Stroebe, \& Aarts, 2007 [restrained eaters]; Roefs \& Jansen, 2002 [obese adults]).

Taken together, findings regarding automatic processes that are associated with eating seem to vary depending on the tested samples and employed paradigms. Different problematic patterns of eating, such as restrained eating, external eating, and associated problems such as obesity, might have different underlying processes. Based on studies thus far, approach-avoidance-related processes appear to contribute to processes that underlie eating behaviour, however. Therefore, the general aim of this study was to investigate food-related automatic approachavoidance-related biases, and to investigate their relation with a less complex and more general eating-related index that is associated to different eating-related problems: Body Mass Index (BMI). In order to do so, we investigated a sample with a wide range of BMI scores and tested whether an imbalance in approach-avoidance is associated with increased BMI. We assessed both approach-avoidance action tendencies (pictorial Approach-Avoidance Task; Rinck \& Becker, 2007) and approach-avoidance associations (verbal Single-Target IAT [ST-IAT]; Wigboldus, Holland, \& Van Knippenberg, 2005; cf. Karpinski \& Steinman, 2006). Since previous research has shown large inconsistencies in positive-negative automatic associations, we also added a verbal ST-IAT assessing positive-negative automatic associations.

As shown by previous research (Brignell et al., 2009; Havermans et al., 2011; Veenstra \& de Jong, 2010; cf. Gladwin et al., 2015), appetitive action tendencies can manifest themselves as either faster food approach or as slower food avoidance. Veenstra and de Jong and Brignell and colleagues computed difference scores and thus did not differentiate between fast approach and slow avoidance, which would both show up as the same difference score reflecting relative approach. Instead, they interpreted their resulting bias scores as an approach bias towards food. However, Havermans et al. analysed approach and avoidance separately. In order to be able to differentiate between faster food approach and slower food avoidance, we also decided to analyse approach and avoidance separately and expected impaired avoidance of snack foods in heavier participants. We expected larger BMI scores to correlate with delayed avoidance action tendencies, weaker avoidance associations, and weaker negative associations. Since people can vary greatly in their preference of sweet versus salty food, we additionally explored correlations between $\mathrm{BMI}$ and action tendencies and affective associations separated by food preference. A rating task was used to assess this preference. Our hypotheses were not different for participants' responses to sweet or salty food stimuli.

\section{Methods}

\section{Participants}

Eighty-four students of Radboud University in Nijmegen, the Netherlands, volunteered to participate in the study. Data of one participant were lost due to technical issues, and could therefore not be included in the analyses. Of the 83 remaining participants $86.75 \%$ were women. Participants demonstrated a wide range of BMI scores (16.53 35.46). Participants had an average BMI of $22.52(s d=3.59)$. Informed consent was signed before the experiment started. Participants received study credit for participating in the experiment. 


\section{Materials and procedure}

The experiment was presented as a collection of tests related to food in order to assess automatic processes related to food. We made several precautions to make sure that participants' food-related implicit processes would be active during the experiment. First, participants were only tested in the afternoon and were asked not to eat for two hours before participating in the study. Additionally, before completing the computer tasks, participants had to complete a taste test. Participants had to sample and rate (crunch, structure, sweetness/saltiness) 3 small pieces of potato chips and 3 small pieces of chocolate candy. The only goal of the taste test was to increase appetite. No research data were collected. Furthermore, since it has been shown that the use of high-fat versus low-fat food can prime the participant with a dieting goal, which might not have been present beforehand (see Houben, Roefs, \& Jansen, 2010), we made sure to always compare high-fat food to neutral stimuli, instead of using low-fat food as a counter category. Stimuli used in all tasks also consisted of an equal amount of sweet and salty snacks, since individuals can vary greatly in their preference of these two types of snacks. After participants completed the experiment, we measured their weight and height.

\section{Approach-Avoidance Task}

Participants started with the Approach-Avoidance Task (AAT; Rinck \& Becker, 2007), which was used to measure approach-avoidance action tendencies. In this task, participants reacted to pictures presented on the computer screen by approaching and avoiding them using a joystick. Pictures were approached by pulling the joystick, whereas they were avoided by pushing the joystick. The joystick was positioned in front of the computer screen, tightly fastened to the table. A task-irrelevant feature was used; participants did not react to the pictures' contents but to the pictures' tilt. Pictures tilted to the left had to be pushed, whereas pictures tilted to the right had to be pulled. Each trial had to be initiated by pressing a button on the joystick with the index finger. Each trial started with the presentation of a single picture in medium size. Participants then had to decide as quickly as possible whether to push or pull the joystick in response to that picture. A zoom function was installed in such a way that pictures increased in size when pulling the joystick and decreased when pushing it. This zoom function increases and disambiguates the visual impression of approach and avoidance, respectively. The picture did not disappear from the screen until the joystick was pushed or pulled completely into the correct direction.

The AAT included three categories of pictures: sweet snacks (chocolate, cake/pie, candy, and cookies), salty snacks (potato chips, nuts, pizzas, and fried snacks), and control pictures (office supplies: paperclips, pencils, staplers, and hole punchers). For every picture category, two different pictures were presented, e.g., two different kinds of chocolates, two different kinds of nuts, two different kinds of staplers, etc. Each snack picture (i.e., sweet and salty) was shown 4 times $(4 \times 2$ snack types $=8)$, and each office supply picture was shown 8 times, so there were as many food-related as non food-related trials. All pictures were pushed and pulled $50 \%$ of the time. After 10 practice trials, the task started with 128 measurement trials. Participants were allowed to take a short break after 64 trials. Participants were able to complete the task between 5 and 10 minutes. Reliability of the AAT (sweet: .41; salty: .85) was not satisfactory with regard to sweet snacks.

\section{Single-Target IAT}

After the AAT, two Single-Target IATs (ST-IAT; Wigboldus et al., 2005; cf. Karpinski \& Steinman, 2006) were administered to assess participants' associations with food. ST-IATs were used instead of IATs, because, as already discussed, we wanted to make sure not to prime participants with a dieting goal, and therefore we needed a task that does not require a counter category. The first ST-IAT assessed approach-avoidance associations with food, whereas the second one assessed positive-negative associations with food. The order of the keys with which food was paired first was counterbalanced; half of the participants started to categorise food with approach/positive, whereas the other half started to categorise food with avoidance/negative. As completing two ST-IATs consecutively might diminish effects in the second ST-IAT (Bluemke \& Friese, 2008), participants carried out an unrelated letter-rating task in between.

Participants had to categorise attributes and targets. Attributes consisted of four four approach- (touching, grabbing, approaching, grasping) and avoidance-related (ignoring, getting around, avoiding, leaving) words in the approach- 
avoidance ST-IAT and of four positive (pleasant, good, fun, nice) and four negative words (horrible, unpleasant, bad, stupid) in the positive-negative ST-IAT. Except for these attributes, the approach-avoidance ST-IAT and the positivenegative ST-IAT were identical. In both versions four sweet and four salty targets were presented: cake, chocolate, candy, pie, pizza, nuts, chips, and croquette. These targets represented the food categories shown during the pictorial AAT. Below, the approach-avoidance ST-IAT is used as the main example and information regarding the positive-negative ST-IAT is provided within parentheses, e.g., avoidance (negative).

As proposed by Wigboldus et al. (2005), each ST-IAT consisted of a sequence of five blocks: (a) attribute categorisation practice, (b) target categorisation practice, (c) first combined block, (d) reversed target categorisation practice, and (e) reversed combined block. During the attribute categorisation practice block including 16 trials, participants had to categorise the attributes (each word had to be categorised twice). Participants were asked to press the key ' $A$ ' in response to approach (positive) words, and the key ' 6 ' on the numeric part of the keyboard in response to avoidance (negative) words. The following block was a target categorisation practice block and included 8 trials. Here, every target was shown once. The third block consisted of 32 trials, and was the first combined block, in which both the attributes and the targets were presented. For half the participants, this block consisted of compatible trials, that is, food words were categorised with the same button as approach (positive) words. For the other half, this block consisted of incompatible trials, such that food words and avoidance (negative) words required the same response. In the fourth block, i.e., the reversed target categorisation practice, the key assignment for the targets changed. This block again included 8 trials. Finally, during the reversed combined block including 32 trials, attributes and targets were again both presented. The participants who were presented with compatible trials in the first combined block were now presented with incompatible trials in this block, and vice versa. Participants needed between 3 and 5 minutes to complete each ST-IAT. Reliability of both the ST-IAT approach-avoidance (sweet: -.14, salty: .26), and the ST-IAT positive-negative (sweet: .05, salty: .17) was extremely low.

\section{Rating task}

At the end of the experiment, participants were presented with all 16 pictures used in the AAT. They were asked to rate each picture ("How much do you like this food?") using a 5-point Likert-scale ranging from 0 (not at all) to 4 (very much).

\section{Statistical analyses}

Before analyses and data aggregation, trials with extreme reaction times $(<300 \mathrm{~ms}$ or $>2000 \mathrm{~ms})$ were removed (AAT: 1.62\%; approach-avoidance ST-IAT: 4.07\%; positive-negative ST-IAT: $0.79 \%$ ). For the ST-IAT analyses incorrect responses (approach-avoidance ST-IAT: $8.78 \%$; positive-negative ST-IAT: $4.88 \%$ ) were also removed. This was not done for the AAT, since participants could not proceed to the next trial until a correct movement was made. However, the error percentage of the first initiated movement was computed for the AAT as well. Participants who made errors on more than $15 \%$ of trials (first initiated movement of the AAT: $n=4$; approach-avoidance ST-IAT: $n=$ 12; positive-negative ST-IAT: $n=1$ ) were excluded from the analysis of the task they made too many errors on.

Regarding the AAT analyses, relative scores were computed by subtracting reaction times (RTs) of sweet and salty snack food pictures from RTs of control pictures. Positive relative scores indicate faster reaction times to food pictures relative to control pictures. These scores were subjected to a 2 (Movement Type: approach, avoidance) x 2 (Snack Type: sweet, salty) repeated-measures ANCOVA with BMI as covariate. Medians were analysed because they are less sensitive to outliers than means. Hence, the reported means represent means of the median. To use mean medians is not unique for our study but rather common in approach-avoidance studies measuring reaction times to investigate implicit processes (see e.g., Rinck \& Bekker, 2007).

With regard to the analyses of the ST-IATs, we approached the data in two ways. In line with conventions, the widely used D-measure (Greenwald, Nosek, \& Banaji, 2003) was used. More specifically, we used the D4 measure, which is calculated as follows: Following the algorithm, all RTs above $10000 \mathrm{~ms}$ were discarded, and error trials were replaced with the mean of the correct trials from the same block, plus a 600 ms penalty. Next, the means for congruent trials were subtracted from the means for the incongruent trials, with higher scores meaning stronger associations between approach/positive and food (congruent) than between avoid/negative and food (incongruent). This score 
was divided by the pooled standard deviation, resulting in the D-score. Practice trials were discarded from analyses, because they were truly practice trials and because responses are not evenly distributed in ST-IAT practice trials. Secondly, similarly to the AAT analysis, we conducted a 2 (Compatility: compatible, incompatible) x 2 (Snack Type: sweet, salty) repeated-measures ANCOVA with BMI as covariate. This enabled us to differentiate between sweet and salty snacks. For these analyses, only trials that presented target stimuli were used. Separate analyses were performed for the approach-avoidance ST-IAT and the positive-negative ST-IAT. All data were analysed using IBM SPSS Statistics version 22.

\section{Results}

\section{Approach-Avoidance Task}

To investigate whether BMI is positively associated with approach of snack food, and/or negatively associated with avoidance of snack food, a 2 (Movement Type: approach, avoidance) x 2 (Snack Type: sweet, salty) repeatedmeasures ANCOVA with BMI as covariate revealed a significant main effect of Snack Type, $F(1,76)=4.90, p=.03$, eta $^{2}=.06$, a significant Snack Type $\times$ BMI interaction, $F(1,76)=4.08, p=.047$, eta ${ }^{2}=.05$, and a significant Movement Type $\times$ Snack Type interaction, $F(1,76)=9.31, p=.003$, eta $^{2}=.11$. There were no significant effects of Movement Type, $F(1,76)=0.95, p=.33$, eta ${ }^{2}=.01$; BMI, $F(1,76)=0.28, p=.60$, eta $^{2}=.00$; or Movement Type $\times \mathrm{BMI}, F(1,76)$ $=2.24, p=.14$ eta $^{2}=.03$. Most importantly, the three-way interaction between Movement Type, Snack Type and BMI was significant, $F(1,76)=9.63, p=.003$, eta $^{2}=.11$. To further explore this interaction, two separate ANCOVAs were conducted, one for approached pictures and one for avoided pictures. This way of analysing is in line with looking at the results with a multidimensional view (see also Gladwin et al., 2015).

Table 1: Approach-Avoidance Task: Means and Standard Deviations for the Reaction Times to All Picture Categories Separately in Milliseconds

\begin{tabular}{lcc}
\hline Movement Type & Food Type & Mean $(\mathbf{s d})$ \\
\hline Approach & Sweet & $691(128)$ \\
& Salty & $702(138)$ \\
& Neutral & $718(131)$ \\
Avoidance & & \\
& Sweet & $713(127)$ \\
& Salty & $731(144)$ \\
& Neutral & $704(111)$ \\
\hline
\end{tabular}

Note: positive relative scores indicate faster reaction times to food pictures relative to control pictures, both for approach and avoidance.

First, we looked at the approach movement: The Snack Type $x$ BMI repeated-measures ANCOVA for approach showed no significant effect of Snack Type, $F(1,76)=0.11, p=.74$, eta ${ }^{2}=.00$; BMI, $F\left(1,76=1.78, p=.19\right.$, eta ${ }^{2}=$ .02 ; or Snack Type x BMI, $F(1,76)=0.28, p=.60$, eta ${ }^{2}=.00$. Secondly, we performed the same analysis for the avoidance movement: The Snack Type $x$ BMI repeated-measures ANCOVA for avoidance did show a significant main effect for Snack Type, $F(1,76)=11.84, p=.001$, eta ${ }^{2}=.14$, but not for BMI, $F(1,76)=0.51, p=.48$, eta ${ }^{2}=.00$. The Snack Type $\times$ BMI interaction was significant, $F(1,76)=11.13, p=.001$, eta ${ }^{2}=.13$, indicating avoidance of snack foods differed as a function of BMI. This analysis was followed up by Univariate ANCOVAs for sweet and salty snacks, which showed that BMI was only associated with avoidance of sweet snacks, $F(1,76)=9.20, p=.003$, eta ${ }^{2}$ $=.11$, and not with avoidance of salty snacks, $F(1,76)=2.57, p=.11$, eta ${ }^{2}=.03$. Also after correcting for multiple testing $(.05 / 4=.0125)$, the results of these post-hoc analyses remained significant. Since BMI correlated significantly and negatively with avoidance of sweet snacks, $r=-.33, p=.003$, but not significantly with avoidance of salty snacks, $r=.18, p=.11$, this suggests that people with a higher BMI had more difficulty avoiding sweet snacks, that is, they showed impaired avoidance of sweet snacks. Means and standard deviations of the raw scores are reported in Table 1. 


\section{Single-Target IAT Approach-avoidance}

The correlation between the D-score and participants' BMI was not significant $(r=-.07, p=.52)$. Next to the more conventional way of analysing the ST-IAT using the D-score, we conducted a 2 (Compatibility: compatible, incompatible) $\times 2$ (Snack Type: sweet, salty) repeated-measures ANCOVA with BMI as covariate. This ANCOVA revealed no significant main or interaction effects: maximum $F(1,69)=2.29, p=.14$, eta ${ }^{2}=.03$. Correlations between BMI and ST-IAT scores (congruent sweet, congruent salty, incongruent sweet, incongruent salty) were low and ranged from -.03 to .13 (all $p>.10$ ). Means and standard deviations are presented in Table 2.

Table 2: Single-Target IATs: Means and Standard Deviations for the Reaction Times on the Target Stimuli in Compatible and Incompatible Trials in Milliseconds

\begin{tabular}{lcc}
\hline ST-IAT Type & Food Type & Mean $(\mathbf{s} \boldsymbol{d})$ \\
\hline Approach-avoidance & & \\
Compatible & Sweet & $604(97)$ \\
& Salty & $632(113)$ \\
Incompatible & Sweet & $663(160)$ \\
& Salty & $706(179)$ \\
Positive-negative & & \\
Compatible & Sweet & $575(101)$ \\
& Salty & $593(117)$ \\
Incompatible & Sweet & $674(125)$ \\
& Salty & $668(144)$ \\
\hline
\end{tabular}

\section{Single-Target IAT Positive-negative}

The correlation between the D-score and participants' BMI was not significant $(r=-.11, p=.33)$. Similarly to the Approach-avoidance ST-IAT, we next conducted a 2 (Compatibility: compatible, incompatible) x 2 (Snack Type: sweet, salty) repeated-measures ANCOVA with BMI as covariate. This ANCOVA only showed a significant main effect of Compatibility, $F(1,80)=6.36, p=.01$, eta ${ }^{2}=.07$ : Participants were faster on compatible trials. There were no other significant effects: maximum $F(1,80)=2.16, p=.15$, eta ${ }^{2}=.03$. Correlations between BMI and ST-IAT scores (congruent sweet, congruent salty, incongruent sweet, incongruent salty) were low and ranged from -.13 to .09 (all $p>$.10). Means and standard deviations are presented in Table 2.

\section{Rating Task}

Liking ratings of both sweet, $t(82)=29.44, p<.001$, and salty, $t(82)=39.79, p<.001$, snacks were significantly larger than zero, meaning that all snacks were evaluated positively. Liking ratings of sweet $(M=2.34, s d=0.72)$ and salty snacks $(M=2.46, s d=0.56)$ did not differ significantly, $t(82)=1.42, p=.16$. To investigate the association between rating scores and BMI, Pearson correlations were calculated between BMI and the total rating score of sweet and salty snacks separately. Both the correlations for BMI and sweet, $r=-.06, p=.59$, and BMI and salty snacks, $r=-$ $.13, p=.26$, were not significant.

\section{Exploratory analyses: food preference}

Food preference was assessed by subtracting the sum rating of salty snacks from the sum rating of sweet snacks. Participants with negative scores preferred salty snacks, whereas participants with positive scores preferred sweet snacks. The mean sweet and salty preference difference score was $-0.94(s d=6.03)$ with a range of $-15.00-10.00$, indicating clear preferences for all participants. Thirty-six participants preferred sweet snacks over salty snacks, whereas 39 participants preferred salty snacks over sweet snacks. Eight participants liked both types of snacks equally. For exploratory reasons, all analyses were carried out separately for those participants who preferred sweet snacks over salty snacks and vice versa. The pattern of results stayed exactly the same, but only for those participants who preferred sweet snacks over salty snacks. More specifically, for the participants who preferred sweet 
snacks, impaired avoidance was associated with higher BMI scores, and the scores for both ST-IATs showed no significant associations with BMI. For participants who preferred salty snacks over sweet snacks, no significant associations were found between BMI on the one hand and the AAT and both ST-IATs on the other hand. For reasons of conciseness, results of these split group analyses are not presented here, but an overview of the results is reported in the Appendix.

\section{Correlations}

To investigate associations between the explicit and implicit processes measured in this study, correlations between the rating task (explicit) on the one hand and the AAT and approach-avoidance and positive-negative ST-IATs (implicit) on the other hand were calculated. Results showed that Pearson correlations were low and ranged from .13 to .14 (all p's $>.10$ ).

Correlations between the AAT and both ST-IATs was also low and ranged from -0.19 to 0.18 (all p's $>.05$ ). Correlations between both ST-IATs were high and mostly significant, however, and ranged from 0.20 to 0.50 (all but 3 p's <.05).

Furthermore, Pearson correlations were calculated between error rates on all tasks and BMI. All correlations were positive and, when adjusted for multiple testing $(.05 / 3=.016)$, the correlations between BMI and AAT $(r=.29, p=$ .009) and ST-IAT approach-avoidance $(r=.28, p=.011)$ error rates were significant. The correlation between BMI and ST-IAT positive-negative error rates $(r=.24, p=.027)$ failed to reach significance. This pattern of correlations shows that people with higher BMI scores made more errors on the tasks.

\section{Discussion}

The present study investigated associations between food-related automatic approach-avoidance biases and BMI. More specifically, the study was designed to investigate the association between BMI on the one hand, and behavioural approach-avoidance tendencies, positive-negative associations, and approach-avoidance associations on the other hand, and thereby aimed at investigating whether an increased BMI was associated with an imbalance in food-related approach-avoidance tendencies.

In line with previous findings (e.g., Brignell et al. 2009; Havermans et al., 2011, \& Veenstra \& de Jong, 2010), results of the AAT showed that BMI was correlated negatively with avoidance of sweet snack foods. In other words, people with increased BMI scores showed more difficulty, i.e., 'impaired avoidance', of sweet snacks. However, this impaired avoidance did not occur for salty snacks. The pattern of results remained the same for participants who preferred sweet snack foods over salty snack foods, when splitting the sample based on sweet versus salty snack preference. This typical finding for sweet snacks might be explained by the fact that sweet snacks are usually consumed throughout the entire day. In contrast, salty snacks, more often than sweet snacks, are typically consumed in the evening. As a result of these temporal aspects, associations with sweet snacks might have been more easily activated by the AAT, because testing occurred in the afternoon.

The negative correlation between BMI and sweet snack foods tentatively suggests that not increased approach tendencies, but impaired avoidance tendencies might explain increased BMI. This may be an important distinction, because it suggests that people with increased BMI scores might not have a problem with approaching food too eagerly, but rather with refraining from food once they have yielded to it. If so, it might be especially difficult for these people to regulate their food intake in an environment where food is abundantly available.

Results of the explicit rating task showed that all food pictures were moderately positively evaluated, and that ratings of sweet and salty snacks did not differ significantly. Correlations between this explicit rating task on the one hand and the implicit tasks on the other hand were generally low. This is in line with low correlations between implicit and explicit measures that are generally found in the literature. The low correlations could be explained by differences in measurement methods (e.g., RTs versus self-report), but also by the fact that implicit and explicit evaluations appear conceptually quite different (see also Hofmann, Gawronski, Gschwender, Le, \& Schmitt, 2005). The low correlations between the AAT on the one hand and both ST-IATs on the other hand, and the high correlations between both STIATs could be explained by the fact that differences in measurement methods indeed play a role here. 
The ST-IATs, used to assess approach-avoidance and positive-negative associations, did not show any association with BMI in any way. Both approach-avoidance associations and positive-negative associations were unrelated to BMI. We found that the reliability of the ST-IATs in this study was particularly low, which might be the most straightforward explanation for the lack of correlations. Moreover, participants found the approach-avoidance ST-IAT difficult to carry out, as shown by the high error rates; twelve participants made errors on more than $15 \%$ of the trials. Therefore, it is unclear how the present findings for the ST-IAT relate to the literature.

A last finding of the present study was that error rates of all tasks showed positive correlations with BMI. This was unexpected. A possible reason for this might be that people with increased BMI scores are more ambivalent towards food or were more distracted by the food and as a result found the tasks more difficult. In addition, this is in line with the idea that obesity is related to impulsivity. That is, impulsivity during the reaction time tasks might be related to poor inhibitory control, leading to more error responses. The link between impulsivity and obesity is supported by research. For example, Davis, Levitan, Muglia, Bewell, and Kennedy (2004) found that obese adults preferred immediate rewards in the face of future losses over smaller immediate rewards and smaller future losses. Nederkoorn, Smulders, Havermans, Roefs, and Jansen (2006) found that obese women were more impulsive than lean women on a delay discounting task.

As mentioned earlier, previous research targeting positive-negative food associations showed inconsistent results. Most studies compared high-fat foods directly to low-fat foods. Only Houben et al. (2010) used a positive-negative ST-IAT similar to ours, using high-fat food as a target, to investigate affective associations in restrained eaters. Houben et al. found that restrained eaters had a more positive association with high-fat foods. To our knowledge, no other studies have yet looked into the relation between approach-avoidance associations and BMI or other eating behaviour indices, using a ST-IAT. Hence, based on the present findings and those of Houben et al., there is reason to continue future research into this area. Future research might also benefit from investigating the association between action tendencies, associations, and attentional biases, since several studies have found a link between attention to food and being overweight (e.g., Castellanos et al., 2009; Werthmann et al., 2011; Yokum, Ng, \& Stice, 2011). Long-term goals might be another important variable to consider. One way to explain our findings for the AAT is to assume that participants with higher BMI scores have stronger goals to lose weight than participants with lower BMI scores, although, to our knowledge, there is no scientific evidence to support this. Nevertheless, one might argue that participants with lower BMI scores do not need to lose weight, and thus might not show impaired avoidance towards high-fat food. On the other hand, previous research findings indicated that goals can have quite the opposite effect. That is, people with a goal to diet can exhibit implicit self-control dispositions, reflected by an approach tendency towards goal-related behaviour (approaching fitness-related stimuli, or healthy food) instead of towards high-caloric food (e.g., Fishbach \& Shah, 2006) or by a negative implicit association with high-fat food (Maas, Keijsers, Tanis, Rinck, \& Becker, 2015). Future research should therefore consider investigating the moderating effect of dieting goals.

Several limitations of the present study should be addressed. The first limitation concerns generalisability of our findings. Although our results might shed light on psychological mechanisms that come into play when body weight increases, future research needs to find out whether impaired avoidance is or is not qualitatively different for obese people. Additionally, although BMI is associated to many eating-related problems, which was the reason we focused on BMI in the present study, certain areas of problematic eating cannot be captured by this index. This means that our results cannot be generalised to all categories of eating-related problems. Second, the fact that the current study was correlational prohibits us from drawing causal conclusions. Although we assume that an imbalance in approachavoidance tendencies can underlie increased BMI, it might just as well be possible that increased BMI leads to the imbalance in food-related approach-avoidance tendencies. Third, we only used a limited range of food types in this study. Although we did present participants with both sweet and salty snacks, we only used four examples of each, which might not necessarily have matched each individual participant's preferences. Indeed, in the explicit liking task it was found that the food types we used in our study were not extremely positively evaluated. Following this, results might have been stronger if we had used stimuli tailored to participants' individual preferences. Fourth, the AAT and ST-IAT used different stimuli modalities. That is, the AAT included pictures, while the ST-IAT used words as stimuli. Furthermore, both tasks are structurally different (e.g., while the AAT uses food as a task-irrelevant feature, participants react to the content of the stimuli in the ST-IAT). Hence, this hampers a direct comparison between the 
two tasks. A fifth limitation is that our sample consisted mostly of female participants, which means that our results do not necessarily apply to males. Although we did not have enough male participants $(n=10)$ to run the analyses on males separately, our results did not change when we removed all male participants from our sample. The last limitation concerns counterbalancing. That is, the tasks were not counterbalanced, which might have decreased our chances of finding results on the ST-IATs, since all participants started with the AAT. However, always presenting the tasks in the same order did fit better with the correlational design of our study. Furthermore, instead of using a fixed block-order, we balanced ST-IAT blocks across participants, which might have lowered sensitivity of the STIAT effects as indices of individual differences, as these are influenced by the extra variance introduced by a balanced block order (Nosek, Greenwald, \& Banaji, 2005).

We used an Approach-Avoidance Task, whereas previous studies (Brignell et al. 2009; Havermans et al., 2011; Veenstra \& de Jong, 2010) used a manikin task. According to Krieglmeyer and Deutsch (2010), who carefully compared the manikin task to two versions of the Approach-Avoidance Task, the manikin task is a more reliable measure. On the other hand, the manikin task makes use of rather symbolic approach avoidance movements, whereas the Approach-Avoidance Task may be more ecologically valid, because approach and avoidance are conceptualised as real motor movements. In recent years, the assessment of actual motor response has received lots of interest in other related areas, for example, in the field of alcohol-related approach avoidance tendencies (Kersbergen, Woud, \& Field, 2015; Van Hemel-Ruiter, de Jong, \& Wiers, 2011; Wiers, Rinck, Kordts, Houben, \& Strack, 2010), so it is only proper to also start examining them in the context of (unwanted) eating behaviour. Furthermore, using the irrelevant-feature Approach-Avoidance Task opens up more possibilities for training and treatment (see also Wiers, Gladwin, \& Rinck, 2013).

In conclusion, this study replicated and extended the existing findings in the literature concerning food-related approach-avoidance action tendencies. We found that BMI was associated with impaired avoidance of sweet snack foods; participants with higher BMI scores showed more difficulty to avoid sweet snacks. We did not find any significant associations between BMI on the one hand and approach-avoidance associations or positive-negative affective associations on the other hand. Reliability of the ST-IATs was particularly low, however, which means that we have to be careful when drawing conclusions. Replication of our results is certainly necessary, and at the moment, we can only tentatively conclude that it is perhaps not an increased approach tendency towards food, but rather an impaired avoidance tendency away from food, which seems to be related to increased BMI scores.

\section{References}

Bluemke, M., \& Friese, M. (2008). Reliability and validity of the Single-Target IAT (ST-IAT): Assessing automatic affect towards multiple attitude objects. European Journal of Social Psychology, 38, 977-997. http://dx.doi.org/10.1002/ejsp.487

Brignell, C., Griffiths, T., Bradley, B.P., \& Mogg, K. (2009). Attentional and approach biases for pictorial food cues. Influence of external eating. Appetite, 52, 299-306. http://dx.doi.org/10.1016/i.appet.2008.10.007

Castellanos, E.H., Charboneau, E., Dietrich, M.S., Park, S., Bradley, B.P., Mogg, K., \& Cowan, R.L. (2009). Obese adults have visual attention bias for food cue images: Evidence for altered reward system function. International Journal of Obesity, 33, 1063-1073. http://dx.doi.org/10.1038/ijo.2009.138

Craeynest, M., Crombez, G., de Houwer, J., Deforche, B., Tanghe, A., \& De Bourdeaudhuij, I. (2005). Explicit and implicit attitudes towards food and physical activity in childhood obesity. Behaviour Research and Therapy, 43, 111-1120. http://dx.doi.org/10.1016/..brat.2004.07.007

Craeynest, M., Crombez, G., Haerens, L., \& De Bourdeaudhuij, I. (2007). Do overweight youngsters like food more than lean peers? Assessing their implicit attitudes with a personalized implicit association task. Food Quality and Preference, 18, 1077-1084. http://dx.doi.org/10.1016/i.foodqual.2007.05.003

Davis, C., Levitan, R.D., Muglia, P., Bewell, C., \& Kennedy, J.L. (2004). Decision-making deficits and overeating: A risk model for obesity. Obesity Research, 12, 929-935. http://dx.doi.org/10.1038/oby.2004.113

De Houwer, J. (2003). The Extrinsic Affective Simon Task. Experimental Psychology, 50, 77-85. http://dx.doi.org/10.1026//1618-3169.50.2.77

De Houwer, J., Custers, R., \& De Clerq, A. (2006). Do smokers have a negative implicit attitude toward smoking? Cognition \& Emotion, 20, 1274-1284. http://dx.doi.org/10.1080/02699930500484506 
De Houwer, J., Crombez, G., Baeyens, F., \& Hermans, D. (2001). On the generality of the affective Simon effect. Cognition \& Emotion, 15, 189-206. http://dx.doi.org/10.1080/02699930125883

Fazio, R.H., Sanbonmatsu, D.M., Powell, M.C., \& Kardes, F.R. (1986). On the automatic activation of attitudes. Journal of Personality and Social Psychology, 50, 229-238 http://dx.doi.org/10.1037/0022-3514.50.2.229

Fishbach, A., \& Shah, J.Y. (2006). Self-control in action: Implicit dispositions toward goals and away from temptations. Journal of Personality and Social Psychology, 90, 820-832. http://dx.doi.org/10.1037/0022$\underline{3514.90 .5 .820}$

Gladwin, T.E., Rinck, M., Eberl, C., Becker, E.S., Lindenmeyer, J., \& Wiers, R.W. (2015). Mediation of cognitive bias modification for alcohol addication via stimulus-specific alcohol avoidance association. Alcoholism: Clinical and Experimental Research, 29, 101-107. http://dx.doi.org/10.1111/acer.12602

Greenwald, A.G., McGhee, D.E., \& Schwartz, J.K.L. (1998). Measuring individual differences in implicit cognition: The Implicit Association Test. Journal of Personality and Social Psychology, 74, 1464-1480. http://dx.doi.org/10.1037/0022-3514.74.6.1464

Greenwald, A.G., Nosek, B.A., \& Banaji, M.R. (2003). Understanding and using the Implicit Assocation Test: I. An improved scoring algorithm. Journal of Personalty and Social Psychology, 85, 197-216. http://dx.doi.org/10.1037/0022-3514.85.2.197

Havermans, R.C., Giesen, J.C.A.H., Houben, K., \& Jansen, A. (2011). Weight, gender, and snack appeal. Eating Behaviors, 12, 126-130. http://dx.doi.org/10.1016/i.eatbeh.2011.01.010

Hill, J.O., \& Peters, J.C. (1998). Environmental contributions to the obesity epidemic. Science, 280, 1371-1374. http://dx.doi.org/10.1126/science.280.5368.1371

Hoefling, A., \& Strack, F. (2008). The tempting effect of forbidden foods: High calorie content evokes conflicting implicit and explicit evaluations in restrained eaters. Appetite, 51, 681-689. http://dx.doi.org/10.1016/j.appet.2008.06.004

Hofmann, W., Gawronski, B., Gschwender, T., Le, H., \& Schmitt, M. (2005). A meta-analysis on the correlation between the implicit association test and explicit self-report measures. Personality and Social Psychology Bulletin, 31, 1169-1185. http://dx.doi.org/10.1177/0146167205275613

Houben, K. , Roefs, A., \& Jansen, A. (2010). Guilty pleasures: Implicit preferences for high calorie food in restrained eating. Appetite, 55, 18-24. http://dx.doi.org/10.1016/j.appet.2010.03.003

Karpinski, A., \& Steinman, R.B. (2006). The Single Category Implicit Association Test as a measure of implicit social cognition. Journal of Personality and Social Psychology, 91, 16-32. http://dx.doi.org/10.1037/0022$\underline{3514.91 .1 .16}$

Kemps E., Tiggemann, M., Martin, R., \& Elliott, M. (2013). Implicit approach-avoidance associations for craved food cues. Journal of Experimental Psychology: Applied, 19, 30-38. http://dx.doi.org/10.1037/a0031626

Kersbergen, I., Woud, M.L., \& Field, M. (2015). The validity of different measures of automatic alcohol action tendencies. Psychology of Addictive Behaviors, 29, 225-230. http://dx.doi.org/10.1037/adb0000009

Krieglmeyer, R., \& Deutsch, R. (2010). Comparing measures of approach-avoidance behaviour: The manikin task vs. two versions of the joystick task. Cognition and Emotion, 24, 810-828. http://dx.doi.org/10.1080/02699930903047298

Maas, J., Keijsers, G.P.J., Rinck, M., Tanis, J., \& Becker, E.S. (2015). Does a dieting goal affect implicit processes and their trainability? Cognitive Therapy and Research, 39, 378-389. http://dx.doi.org/10.1007/s10608-014$\underline{9658-0}$

Mogg, K., Bradley, B.P., Field, M., \& De Houwer, J. (2003). Eye movements to smoking-related pictures in smokers: relationship between attentional biases and implicit and explicit measures of stimulus valence. Addiction, 98, 825-836. http://dx.doi.org/10.1046/j.1360-0443.2003.00392.x

Nederkoorn, C., Smulders, F.T.Y., Havermans, R.C., Roefs, A., \& Jansen, A. (2006). Impulsivity in obese women. Appetite, 47, 253-256. http://dx.doi.org/10.1016/j.appet.2006.05.008

Nosek, B.A., Greenwald, A.G., \& Banaji, M.R. (2005). Understanding and using the Implicit Association Test: II. Method variables and construct validity. Personality and Social Psychology Bulletin, 31, 166-180. http://dx.doi.org/10.1177/0146167204271418

Ogden, C.L., Carroll, M.D., Kit, B.K., \& Flegal, K.M. (2012). Prevalence of obesity in the United States, 2009-2010. NCHS Data Brief, 82, 1-8. 
Palfai, T.P., \& Ostafin, B.D. (2003). Alcohol-related motivational tendencies in hazardous drinkers: Assessing implicit response tendencies using the modified IAT. Behaviour Research and Therapy, 41, 1149-1162. http://dx.doi.org/10.1016/S0005-7967(03)00018-4

Papies, E., Stroebe, W., \& Aarts, H. (2007). Pleasure in the mind: restrained eating and spontaneous hedonic thoughts about food. Journal of Experimental Social Psychology, 43, 810-817. http://dx.doi.org/10.1016/i.jesp.2006.08.001

Roefs, A., \& Jansen, A. (2002). Implicit and explicit attitudes toward high-fat foods in obesity. Journal of Abnormal Psychology, 111, 517-521. http://dx.doi.org/10.1037/0021-843X.111.3.517

Rinck, M., \& Becker, E.S. (2007). Approach and avoidance in fear of spiders. Behaviour Research and Therapy, 38, 105-120. http://dx.doi.org/10.1016/j.jbtep.2006.10.001

Strack, F., \& Deutsch, R. (2004). Reflective and impulsive determinants of social behaviour. Personality and Social Psychology Review, 8, 220-247. http://dx.doi.org/10.1207/s15327663jcp1603 2

Van Hemel-Ruiter, M.E., de Jong, P.J., \& Wiers, R.W. (2011). Appetitive and regulatory processes in young adolescent drinkers. Addictive Behaviors, 36, 18-26. http://dx.doi.org/10.1016/i.addbeh.2010.08.002

Van Strien, T., Frijters, J., Bergers, G., \& Defares, P. (1986). The Dutch Eating Behaviour Questionnaire (DEBQ) for assessment of restrained, emotional, and external eating behaviour. International Journal of Eating Disorders, 5, 295-315. http://dx.doi.org/10.1002/1098-108X(198602)5:2<295::AID-EAT2260050209>3.0.CO;2-T

Veenstra, E.M., \& de Jong, P.J. (2010). Restrained eaters show enhanced automatic approach tendencies towards food. Appetite, 55, 30 -36. http://dx.doi.org/10.1016/i.appet.2010.03.007

Werthmann, J., Roefs, A., Nederkoorn, C., Mogg, K., Bradley, B.P., \& Jansen, A. (2011) Can(not) take my eyes off it: Attention bias for food in overweight participants. Health Psychology, 30, 561-569. http://dx.doi.org/10.1016/j.appet.2012.05.107

Wiers, R.W., Gladwin, T.E, \& Rinck, M. (2013). Should we train alcohol-dependent patients to avoid alcohol? Frontiers in Psychiatry, 4, 1-2. http://dx.doi.org/10.3389/fpsyt.2013.00033

Wiers, R.W., Rinck, M., Kordts, R., Houben, K., \& Strack, F. (2010). Re-training automatic action-tendencies to approach alcohol in hazardous drinkers. Addiction, 105, 279-287. http://dx.doi.org/10.1177/0956797611400615

Wigboldus, D.H.J., Holland, R.W., \& van Knippenberg, A. (2005). Single Target Implicit Associations. Unpublished manuscript.

Yokum, S., Ng, J., \& Stice, E. (2011). Attentional bias to food images associated with elevated weight and future weight gain: An fMRI study. Obesity, 19, 1775-1183. http://dx.doi.org/10.1038/oby.2011.168 


\section{Appendix}

An Overview of the Main Results Separated for Snack Preference: Sweet Versus Salty

\begin{tabular}{|c|c|c|c|c|}
\hline Task & Group & Analysis & Effect & $F$ (p-value) \\
\hline \multirow[t]{14}{*}{$\begin{array}{l}\text { Approach- } \\
\text { Avoidance Task }\end{array}$} & Combined & $\begin{array}{l}2 \text { (Movement Type: approach, } \\
\text { avoidance) x } 2 \text { (Snack Type: } \\
\text { sweet, salty) x BMI }\end{array}$ & Snack Type & $4.90(<.05)$ \\
\hline & & & Movement Type & $0.95(.14)$ \\
\hline & & & BMI & $0.28(.60)$ \\
\hline & & & Snack Type x BMI & $9.31(<.01)$ \\
\hline & & & Movement Type x BMI & $2.24(<.01)$ \\
\hline & & & $\begin{array}{l}\text { Snack Type x Movement Type } \\
\text { x BMI }\end{array}$ & $9.63(<.01)$ \\
\hline & & $\begin{array}{l}\text { Approach: } 2 \text { (Snack Type: sweet, } \\
\text { salty) x BMI }\end{array}$ & Snack Type & $0.11(.74)$ \\
\hline & & & BMI & $1.78(.19)$ \\
\hline & & & Snack Type x BMI & $0.28(.60)$ \\
\hline & & $\begin{array}{l}\text { Avoidance: } 2 \text { (Snack Type: } \\
\text { sweet, salty) x BMl }\end{array}$ & Snack Type & $11.84(<.01)$ \\
\hline & & & BMI & $0.51(.48)$ \\
\hline & & & Snack Type x BMI & $11.13(<.01)$ \\
\hline & & Avoidance: sweet & BMI & $9.20(<.01)$ \\
\hline & & Avoidance: salty & $\mathrm{BMI}$ & $2.57(.11)$ \\
\hline \multirow[t]{6}{*}{$\begin{array}{l}\text { Single-Target IAT } \\
\text { approach- } \\
\text { avoidance }\end{array}$} & & $\begin{array}{l}2 \text { (Compatibilty: compatible, } \\
\text { incompatible) x } 2 \text { (Snack Type: } \\
\text { sweet, salty) x BMI }\end{array}$ & Snack Type & $0.21(.65)$ \\
\hline & & & Compatibility & $0.37(.55)$ \\
\hline & & & BMI & $0.20(.66)$ \\
\hline & & & Snack Type x Compatibility & $1.98(.16)$ \\
\hline & & & Snack Type x BMI & $0.00(.99)$ \\
\hline & & & $\begin{array}{l}\text { Snack Type x Compatibility x } \\
\text { BMI }\end{array}$ & $2.29(.14)$ \\
\hline \multirow[t]{6}{*}{$\begin{array}{l}\text { Single-Target IAT } \\
\text { positive-negative }\end{array}$} & & $\begin{array}{l}2 \text { (Compatibilty: compatible, } \\
\text { incompatible) x } 2 \text { (Snack Type: } \\
\text { sweet, salty) x BMI }\end{array}$ & Snack Type & $0.72(.40)$ \\
\hline & & & Compatibility & $6.36(<.05)$ \\
\hline & & & BMI & $0.03(.86)$ \\
\hline & & & Snack Type x Compatibility & $0.94(.34)$ \\
\hline & & & Snack Type x BMI & $0.56(.46)$ \\
\hline & & & $\begin{array}{l}\text { Snack Type x Compatibility } x \\
\text { BMI }\end{array}$ & $1.39(.24)$ \\
\hline
\end{tabular}




\begin{tabular}{|c|c|c|c|c|}
\hline Task & Group & Analysis & Effect & $F$ ( $p$-value) \\
\hline \multirow[t]{14}{*}{$\begin{array}{l}\text { Approach- } \\
\text { Avoidance Task }\end{array}$} & $\begin{array}{l}\text { Sweet } \\
\text { preference }\end{array}$ & $\begin{array}{l}2 \text { (Movement Type: approach, } \\
\text { avoidance) x } 2 \text { (Snack Type: } \\
\text { sweet, salty) x BMI }\end{array}$ & Snack Type & $2.10(0.16)$ \\
\hline & & & Movement Type & $9.11(<.01)$ \\
\hline & & & BMI & $0.29(.60)$ \\
\hline & & & Snack Type x BMI & $1.86(.18)$ \\
\hline & & & Movement Type x BMI & $13.11(<.01)$ \\
\hline & & & $\begin{array}{l}\text { Snack Type x Movement Type } \\
\text { x BMI }\end{array}$ & $9.36(<.01)$ \\
\hline & & $\begin{array}{l}\text { Approach: } 2 \text { (Snack Type: sweet, } \\
\text { salty) x BMI }\end{array}$ & Snack Type & $0.85(.36)$ \\
\hline & & & BMI & $5.70(<.05)$ \\
\hline & & & Snack type x BMI & $0.95(.34)$ \\
\hline & & $\begin{array}{l}\text { Avoidance: } 2 \text { (Snack Type: } \\
\text { sweet, salty) x BMI }\end{array}$ & Snack Type & $7.47(<.05)$ \\
\hline & & & BMI & $2.45(.13)$ \\
\hline & & & Snack Type x BMI & $7.04(<.05)$ \\
\hline & & Avoidance: sweet & BMI & $11.23(<.01)$ \\
\hline & & Avoidance: salty & BMI & $1.05(.31)$ \\
\hline \multirow{7}{*}{$\begin{array}{l}\text { Single-Target IAT } \\
\text { approach- } \\
\text { avoidance } \\
\text { (correlation D4 } \\
\text { with BMI: } r=- \\
.03, p=.85 \text { ) }\end{array}$} & & $\begin{array}{l}2 \text { (Compatibility: compatible, } \\
\text { incompatible) } \times 2 \text { (Snack Type: } \\
\text { sweet, salty) } \times \text { BMI }\end{array}$ & Snack Type & $0.00(.96)$ \\
\hline & & & & \\
\hline & & & Compatibility & $0.02(.88)$ \\
\hline & & & BMI & $0.23(.63)$ \\
\hline & & & Snack Type x Compatibility & $1.09(.31)$ \\
\hline & & & Snack Type x BMI & $0.17(.68)$ \\
\hline & & & $\begin{array}{l}\text { Snack Type x Compatibility } x \\
\text { BMI }\end{array}$ & $2.31(.14)$ \\
\hline \multirow{6}{*}{$\begin{array}{l}\text { Single-Target IAT } \\
\text { positive-negative } \\
\text { (correlation D4 } \\
\text { with BMI: } r=- \\
.07, p=.68 \text { ) }\end{array}$} & & $\begin{array}{l}2 \text { (Compatibility: compatible, } \\
\text { incompatible) } \times 2 \text { (Snack Type: }\end{array}$ & Snack Type & $0.18(.68)$ \\
\hline & & & Compatibility & $1.30(.26)$ \\
\hline & & & BMI & $0.34(.57)$ \\
\hline & & & Snack Type $x$ Compatibility & $0.67(.42)$ \\
\hline & & & Snack Type x BMI & $0.07(.79)$ \\
\hline & & & $\begin{array}{l}\text { Snack Type } x \text { Compatibility } x \\
\text { BMI }\end{array}$ & $0.50(.48)$ \\
\hline \multirow[t]{3}{*}{$\begin{array}{l}\text { Approach- } \\
\text { Avoidance Task }\end{array}$} & Salty preference & $\begin{array}{l}2 \text { (Movement Type: approach, } \\
\text { avoidance) } \times 2 \text { (Snack Type: } \\
\text { sweet, salty) } \times \text { BMI }\end{array}$ & Snack Type & $2.77(.11)$ \\
\hline & & & Movement Type & $0.15(.70)$ \\
\hline & & & BMI & $0.07(.79)$ \\
\hline
\end{tabular}




\begin{tabular}{|c|c|c|c|c|}
\hline Task & Group & Analysis & Effect & $F$ ( $p$-value $)$ \\
\hline & & & Snack Type x BMI & $2.41(.13)$ \\
\hline & & & Movement Type x BMI & $0.04(.84)$ \\
\hline & & & $\begin{array}{l}\text { Snack Type x Movement Type } \\
\text { x BMI }\end{array}$ & $1.49(.23)$ \\
\hline \multirow{6}{*}{\multicolumn{2}{|c|}{$\begin{array}{l}\text { Single-Target IAT } \\
\text { approach- } \\
\text { avoidance } \\
\text { (correlation D4 } \\
\text { with BMI: } r=- \\
.13, p=.44 \text { ) }\end{array}$}} & $\begin{array}{l}2 \text { (Compatibility: compatible, } \\
\text { incompatible) x } 2 \text { (Snack Type: } \\
\text { sweet, salty) x BMI }\end{array}$ & Snack Type & $1.43(.24)$ \\
\hline & & & Compatibility & $0.35(.56)$ \\
\hline & & & BMI & $0.58(.45)$ \\
\hline & & & Snack Type x Compatibility & $0.04(.84)$ \\
\hline & & & Snack Type x BMI & $1.14(.29)$ \\
\hline & & & $\begin{array}{l}\text { Snack Type x Compatibility x } \\
\text { BMI }\end{array}$ & $0.19(.67)$ \\
\hline \multirow{6}{*}{$\begin{array}{l}\text { Single-Target IAT } \\
\text { positive-negative } \\
\text { (correlation D4 } \\
\text { with BMI: } r=- \\
.13, p=.43 \text { ) }\end{array}$} & & $\begin{array}{l}2 \text { (Compatibility: compatible, } \\
\text { incompatible) x } 2 \text { (Snack Type: }\end{array}$ & Snack Type & $0.26(.62)$ \\
\hline & & & Compatibility & $5.8(<.05)$ \\
\hline & & & BMI & $0.30(.58)$ \\
\hline & & & Snack Type x Compatibility & $0.56(.46)$ \\
\hline & & & Snack Type x BMI & $0.24(.63)$ \\
\hline & & & $\begin{array}{l}\text { Snack Type x Compatibility x } \\
\text { BMI }\end{array}$ & $1.74(.20)$ \\
\hline
\end{tabular}

